\title{
PEMODELAN GEOGRAPHICALLY WEIGHTED REGRESSION (GWR) PADA PERSENTASE KRIMINALITAS DI PROVINSI JAWA TIMUR TAHUN 2017
}

\author{
Dessy W S Yusuf ${ }^{1}$, Elvira M P Hermanto², and Wara Pramesti ${ }^{3}$ \\ ${ }^{1}$ Program Studi Statistika, Universitas PGRI Adi Buana Surabaya (UNIPA Surabaya), Indonesia, \\ dessywulandarisy@gmail.com \\ ${ }^{2}$ Program Studi Statistika, Universitas PGRI Adi Buana Surabaya (UNIPA Surabaya), Indonesia, \\ elvira@unipasby.ac.id \\ ${ }^{3}$ Program Studi Statistika, Universitas PGRI Adi Buana Surabaya (UNIPA Surabaya), Indonesia, \\ warapra@unipasby.ac.id
}

Indonesian Journal of Statistics and Its Applications (eISSN:2599-0802)

Vol 4 No 1 (2020), 156 - 163

Copyright ( 2020 Dessy W S Yusuf, Elvira M P Hermanto, and Wara Pramesti. This is an open-access article distributed under the Creative Commons Attribution License, which permits unrestricted use, distribution, and reproduction in any medium, provided the original work is properly cited.

\begin{abstract}
Crime is everything that exists in Indonesia. Based on BPS data in 2018, East Java Province ranks first in the Province of North Sumatra and the Special Capital Region of Jakarta. This research was conducted to determine the factors that support crime in each Regency / City of East Java Province. The method used in this research is Weighted Geographic Regression (GWR). Geographically Weighted Regression (GWR) is one of the statistical methods used to model variable responses with regional or areabased predictor variables. Based on the GWR results, it is recognized as a variable Population Density Percentage (X1), Open Unemployment Rate (X2), Poor Population (X3), Population who are Victims of Drug Abuse (X4), Human Development Index (X5), and Married Human Population (X6) ) importance in the city of Surabaya. The coefficient of determination (R2) and AIC from GWR is better than the OLS model. This refers to the optimal R2 and AIC values of $91.40 \%$ and 129.293 .
\end{abstract}

Keywords: akaike's information criterion (aic), criminality, geographically weighted regression.

*Received Aug 2019; Accepted Feb 2020; Published online on Feb 2020 


\section{Pendahuluan}

Kriminalitas merupakan sebuah tindakan yang bersifat negatif, dimana setiap pelakunya akan dijerat dengan berbagai macam pasal yang telah diatur penerapannya di dalam undang - undang yang berlaku. Kriminalitas merupakan perbuatan seseorang yang dapat diancam hukuman berdasarkan KUHP atau Undang - Undang serta peraturan lainnya di Indonesia. BPS (2018b) pada Statistika Kriminal Indonesia tahun 2018 menyatakan bahwa angka kriminalitas pada tahun 2017 mengalami kenaikan cukup drastis dibandingkan dengan tahun 2016. Tahun 2017 angka kriminalitas di Provinsi Jawa Timur mencapai 34.59 jumlah kejahatan menurut jenis tindak pidana. Beberapa kasus kriminalitas paling tinggi yang terjadi selama tahun 2017 diantaranya penggunaan narkotika dan psikotropika, pencurian serta penipuan sedangkan tindak kriminalitas di Provinsi Jawa Timur yang mengalami kenaikan dari tahun 2015 - 2017 adalah pencabulan, memperkerjakan anak di bawah umur, pencurian dan penganiyayaan berat.

Berbagai penelitian telah dilakukan untuk mengetahui hubungan antara persentase kriminalitas dengan variabel yang mempengaruhi salah satu metode yang digunakan adalah regresi klasik. Akan tetapi, metode tersebut tidak menekankan aspek humaniora, seperti tingkat kriminalitas yang direpresentasikan pada suatu daerah kabupaten/kota masih terbatas untuk dikaji. Geographically Weighted Regression (GWR) merupakan salah satu metode statistik yang digunakan untuk memodelkan variabel respon dengan variabel prediktor yang berbasis wilayah atau area (Anselin, 2013; Anselin \& Bera, 1998; Fotheringham et al., 2003). Keunggulan model GWR dibandingkan dengan model regresi klasik adalah GWR mampu memberikan model secara lokal, selain itu GWR juga mampu menunjukkan faktor - faktor yang mempengaruhi variabel respon terhadap aspek dalam spasial (lokasi).

Berdasarkan penjelasaan tersebut, maka pada penelitian ini akan dilakukan pemodelan persentase kriminalitas di Provinsi Jawa Timur berdasarkan faktor - faktor yang diduga mempengaruhi, antara lain persentase kepadatan penduduk, tingkat pengangguran terbuka dan penduduk miskin. Dengan menggunakan metode GWR diharapkan dapat menjelaskan dan mengidentifikasikan faktor - faktor yang mempengaruhi persentase kriminalitas di Provinsi Jawa Timur berdasarkan aspek lokasi. Hal ini yang melatarbelakangi peneliti untuk melakukan suatu penelitian yang berjudul "Pemodelan Geographically Weighted Regression (GWR) Pada Persentase Kriminalitas di Provinsi Jawa Timur Tahun 2017".

\section{Metodologi}

\subsection{Sumber Data dan Variabel Penelitian}

Data oleh BPS (2018a) merupakan data publikasi dengan judul "Provinsi Jawa Timur Dalam Angka 2018". Unit observasi dalam penelitian ini adalah Kabupaten/Kota yang ada di Provinsi Jawa Timur. Variabel-variabel yang digunakan pada penelitian ini adalah Persentase Kriminalitas $(Y)$, Persentase Kepadatan Penduduk $\left(X_{1}\right)$, Tingkat Pengangguran Terbuka $\left(X_{2}\right)$, Penduduk Miskin $\left(X_{3}\right)$, Penduduk yang merupakan Korban Penyalahgunaan NAPZA $\left(X_{4}\right)$, Indeks Pembangunan Manusia $\left(X_{5}\right)$ dan Penduduk Pernah Menikah $\left(X_{6}\right)$. 


\subsection{Metode Penelitian}

Langkah analisis yang digunakan dalam penelitian ini adalah sebagai berikut:

1. Mendeskripsikan data dengan menggunakan peta tematik sebagai gambaran keadaan persentase kriminalitas di Provinsi Jawa Timur.

2. Mengidentifikasi adanya multikolinieritas dengan menggunakan nilai VIF dan korelasi pearson (Gujarati \& Porter, 2012).

3. Melakukan pemodelan persentase kriminalitas dengan faktor-faktor yang mempengaruhi di Provinsi Jawa Timur.

a. Melakukan estimasi parameter untuk memodelkan variabel respon dengan variabel prediktor dengan metode OLS.

b. Melakukan uji signifikansi parameter regresi linier berganda secara serentak dan parsial.

c. Melakukan uji asumsi residual dan uji efek spasial (Breush-Pagan) (LeSage, 2008).

4. Menghitung jarak Eucliden $d_{i j}$ antara lokasi ke-i pada koordinat ${ }_{\left(u_{i}, v_{i}\right)}$ terhadap lokasi ke-j pada koordinat $\left(u_{j}, v_{j}\right)$.

5. Memilih pembobot antara fungsi kernel Fixed Gaussian dan kernel Adaptive Gaussian dengan nilai Cross Validation (CV) yang minimum.

6. Menghitung matriks pembobot dengan bandwidth optimum.

7. Mendapatkan estimasi parameter untuk model GWR di setiap lokasi.

8. Melakukan pengujian kesesuaian model Goodness of Fit untuk GWR di setiap lokasi (Leung et al., 2000).

9. Melakukan pengujian secara parsial pada parameter GWR

10. Mendeskripsikan karakteristik persebaran faktor-faktor yang mempengaruhi kriminalitas di Provinsi Jawa Timur menggunakan peta tematik.

11. Mendapatkan model terbaik untuk persentase kriminalitas di Provinsi Jawa Timur dengan menggunakan AIC dan nilai Pseudo $\mathrm{R}^{2}$.

\section{Hasil dan Pembahasan}

\subsection{Analisis Deskriptif}

Gambar 1 menunjukkan kerawanan tingkat kriminalitas yang digambarkan dengan gradien warna. Rata-rata persentase kriminalitas di Provinsi Jawa Timur adalah 2.63. Kota Surabaya merupakan Kota dengan tingkat kriminalitas tertinggi sebesar 17.34 sedangkan Kabupaten Pacitan merupakan Kabupaten dengan persentase kriminalitas terendah di Provinsi Jawa Timur pada tahun 2017 yaitu sebesar 0.25.

\subsection{Pemeriksaan Multikolinieritas}

Pemeriksaan multikolinieritas ditunjukkan dengan nilai VIF. Adanya hubungan antar variabel prediktor pada model regresi linier berganda ditunjukkan ketika nilai VIF lebih dari 10. Nilai VIF pada setiap variabel prediktor kurang dari 10 sehingga dapat disimpulkan bahwa tidak terjadi multikolinieritas antar variabel prediktor (Tabel 1). 


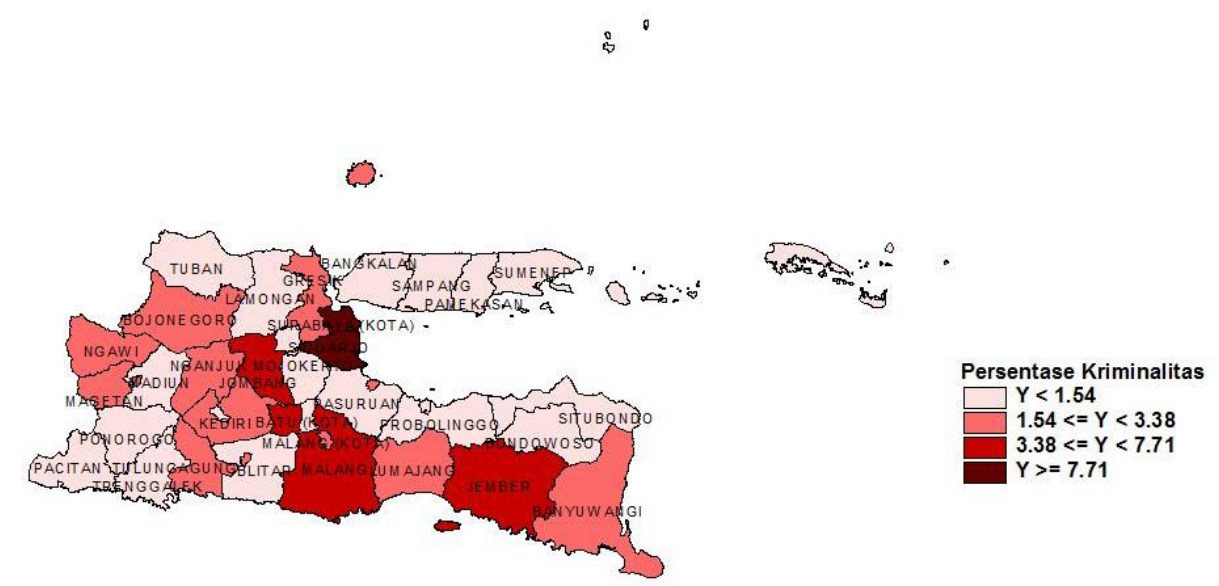

Gambar 1: Peta persebaran kriminalitas di kabupaten/kota provinsi jawa timur 2017.

Tabel 1: Nilai VIF yang diperoleh.

\begin{tabular}{cc}
\hline Variabel & VIF \\
\hline $\mathrm{X}_{1}$ & 3.45 \\
$\mathrm{X}_{2}$ & 2.04 \\
$\mathrm{X}_{3}$ & 2.33 \\
$\mathrm{X}_{4}$ & 1.21 \\
$\mathrm{X}_{5}$ & 3.74 \\
$\mathrm{X}_{6}$ & 1.48 \\
\hline
\end{tabular}

\subsection{Pemodelan Regresi Linier}

Regresi global menggunakan regresi linier berganda dilakukan untuk mengetahui arah hubungan kausalitas ke-enam variabel prediktor dengan tingkat kriminalitas sebagai variabel respon di Provinsi Jawa Timur Tahun 2017. Berdasarkan hasil Pengujian serentak dengan uji $F$, diketahui bahwa terdapat pengaruh secara bersama-sama pada keenam variabel prediktor terhadap persentase kriminalitas di Provinsi Jawa Timur. Hal ini ditunjukkan oleh nilai signifikansi yang lebih kecil dari $\alpha=5 \%$. Selain itu, diketahui bahwa terdapat dua variabel yang signifikan terhadap variabel Persentase Kriminalitas yaitu variabel penduduk miskin $\left(X_{3}\right)$ dan Indeks Pembangunan Manusia (X) karena memiliki P-Value kurang dari $\alpha=5 \%$ (Tabel 2).

Berdasarkan Tabel 2 diperoleh persamaan regresi global adalah sebagai berikut:

$$
\hat{Y}=-36.16+0.36 X_{1}-0.06 X_{2}+0.04 X_{3}-0.14 X_{4}+0.49 X_{5}-0.06 X_{6}
$$

Jika Penduduk Miskin $\left(X_{3}\right)$ naik sebesar satu persen maka persentase kriminalitas akan naik sebesar $0.04 \%$ dengan syarat variabel lain konstan. Jika Indeks Pembangunan Manusia $\left(X_{5}\right)$ naik sebesar satu persen maka persentase kriminalitas akan naik sebesar $0.49 \%$ dengan syarat variabel lain konstan. 
Tabel 2: Pengujian parameter regresi global.

\begin{tabular}{crrr}
\hline $\begin{array}{c}\text { Estimasi } \\
\text { Parameter }\end{array}$ & $\begin{array}{c}\text { Nilai } \\
\text { Estimasi }\end{array}$ & \multicolumn{1}{c}{$\boldsymbol{T}$} & \multicolumn{1}{c}{$\begin{array}{c}\text { Nilai } \\
\text { Sig. }\end{array}$} \\
\hline$\hat{\beta}_{0}$ & -36.16 & -3.25 & ${ }^{*} 0.00$ \\
$\hat{\beta}_{1}$ & 0.36 & 1.41 & 0.16 \\
$\hat{\beta}_{2}$ & -0.06 & -0.14 & 0.89 \\
$\hat{\beta}_{3}$ & 0.04 & 4.53 & ${ }^{*} 0.00$ \\
$\hat{\beta}_{4}$ & -0.14 & -1.39 & 0.17 \\
$\hat{\beta}_{5}$ & 0.49 & 3.25 & ${ }^{*} 0.00$ \\
$\hat{\beta}_{6}$ & -0.06 & -0.16 & 0.87 \\
FHitung $=7.18 ;$ P-Value $=0.00$ & \\
\hline \multicolumn{4}{l}{$\mathrm{R}^{2}=0.58$} \\
\multicolumn{4}{l}{ Keterangan: ${ }^{*}$ ) Signifikan pada $\alpha=5 \%$}
\end{tabular}

\subsection{Uji Asumsi Residual Identik}

Berdasarkan hasil pengujian asumsi residual dengan uji Breush-Pagan tidak memenuhi asumsi residual identik. Hal tersebut ditunjukkan dengan nilai signifikansi sebesar 0.01 lebih kecil dari nilai $\alpha=5 \%$. Oleh sebab itu, terlanggarnya asumsi residual identik menguatkan dugaan adanya aspek lokasi. Sehingga dapat dilakukan untuk memodelkan persentase kriminalitas di Provinsi Jawa Timur dengan menggunakan pemodelan GWR.

\subsection{Uji Asumsi Residual Independen}

Berdasarkan hasil pengujian asumsi independensi dengan menggunakan durbin watson diketahui bahwa tidak ada autokorelasi antar residual. Hal tersebut ditunjukkan oleh nilai signifikansi yang lebih besar dari $\alpha=5 \%$ yakni sebesar 0.48 serta Durbin Watson yang diperoleh sebesar 1.88. Dimana, nilai tersebut berada diantara $d U<d<(4-d U)$ atau $1.864<1.88<2.135$.

\subsection{Uji Asumsi Distribusi Normal}

Pengujian asumsi distribusi normal menggunakan uji kolmogorov-smirnov. Diketahui bahwa residual dinyatakan berdistribusi normal. Hal tersebut ditunjukkan oleh hasil signifikansi pengujian kolmogorov-smirnov yang lebih besar dari $\alpha=5 \%$ yaitu 0.07 .

\subsection{Pemilihan Pembobot Optimum}

Setelah aspek heterogenitas spasial menunjukkan adanya dugaan aspek lokasi, selanjutnya dilakukan pemilihan pembobot optimum. Pemilihan pembobot optimum dengan menggunakan kriteria nilai Cross Validation dari setiap pembobot. Berdasarkan Tabel 3, dapat diketahui bahwa nilai CV paling minimum diperoleh 
dengan menggunakan fungsi pembobot adaptive gaussian yaitu dengan CV minimum sebesar 166.21. Oleh karena itu, dalam memodelkan persentase kriminalitas dengan GWR menggunakan pembobot Adaptive Gaussian.

Tabel 3: Pembobot optimum yang diperoleh.

\begin{tabular}{lc}
\hline \multicolumn{1}{c}{$\begin{array}{c}\text { Fungsi } \\
\text { Pembobot }\end{array}$} & $\begin{array}{c}\text { CV } \\
\text { minimum }\end{array}$ \\
\hline Fixed & 363.82 \\
Gaussian & \\
Adaptive & 166.21 \\
Gaussian & \\
\hline
\end{tabular}

\subsection{Pendugaan Parameter Setiap Lokasi}

Tabel 4 menunjukkan rentang nilai estimasi parameter model GWR. Terdapat nilai minimum dan maksimum yang menunjukkan bahwa terdapat nilai estimasi parameter yang berbeda setiap lokasi. Berdasarkan Tabel 4 menunjukkan bahwa estimasi parameter pada variabel $X_{3}$ dan $X_{5}$ memiliki koefisien parameter regresi yang bernilai positif pada semua Kabupaten/Kota sedangkan nilai parameter $\mathrm{X}_{1}, \mathrm{X}_{2}, \mathrm{X}_{4}$ dan $\mathrm{X}_{6}$ yang memiliki koefisien parameter regresi negatif hingga positif yang menunjukkan perbedaan nilai pengaruh terhadap tingkat kriminalitas antar Kabupaten/Kota di Provinsi Jawa Timur.

Tabel 4: Estimasi parameter model GWR.

\begin{tabular}{crr}
\hline Variabel & Minimum & Maksimum \\
\hline$\hat{\beta}_{0}$ & -54.23 & -14.86 \\
$\hat{\beta}_{1}$ & -0.46 & 0.45 \\
$\hat{\beta}_{2}$ & -0.09 & 1.75 \\
$\hat{\beta}_{3}$ & 0.00 & 0.07 \\
$\hat{\beta}_{4}$ & -0.93 & 0.00 \\
$\hat{\beta}_{5}$ & 0.22 & 1.48 \\
$\hat{\beta}_{6}$ & -5.84 & 0.46 \\
\hline
\end{tabular}

\subsection{Pengujian Kesesuaian Model}

Pengujian kesesuaian model digunakan untuk mengetahui apakah ada perbedaan yang signifikan antara model OLS dengan model GWR. Tabel 5 menunjukkan bahwa $F_{\text {hitung }}$ kurang dari $F_{\text {tabel }}$ yang berarti terdapat perbedaan yang signifikan antara model OLS dengan model GWR. 
Tabel 5: Uji kesesuaian model.

\begin{tabular}{ccccc}
\hline Model & SS & F hitung & F tabel $\begin{array}{c}\text { P- } \\
\text { Value }\end{array}$ \\
\hline OLS & 196.29 & 0.44 & 0.51 & ${ }^{*} 0.02$ \\
GWR & 39.99 & \\
\hline \multicolumn{5}{l}{ Keterangan: ${ }^{*}$ Signifikan pada $\alpha=5 \%$}
\end{tabular}

\subsection{Pengelompokan Variabel Signifikan}

Gambar 2 menunjukkan persebaran variabel prediktor yang berpengaruh di tiap Kabupaten/Kota di Provinsi Jawa Timur. Terlihat bahwa terdapat pengelompokkan wilayah peyebaran kriminalitas di Provinsi Jawa Timur. Hal tersebut dikarenakan adanya perbedaan variabel yang signifikan di setiap wilayah.

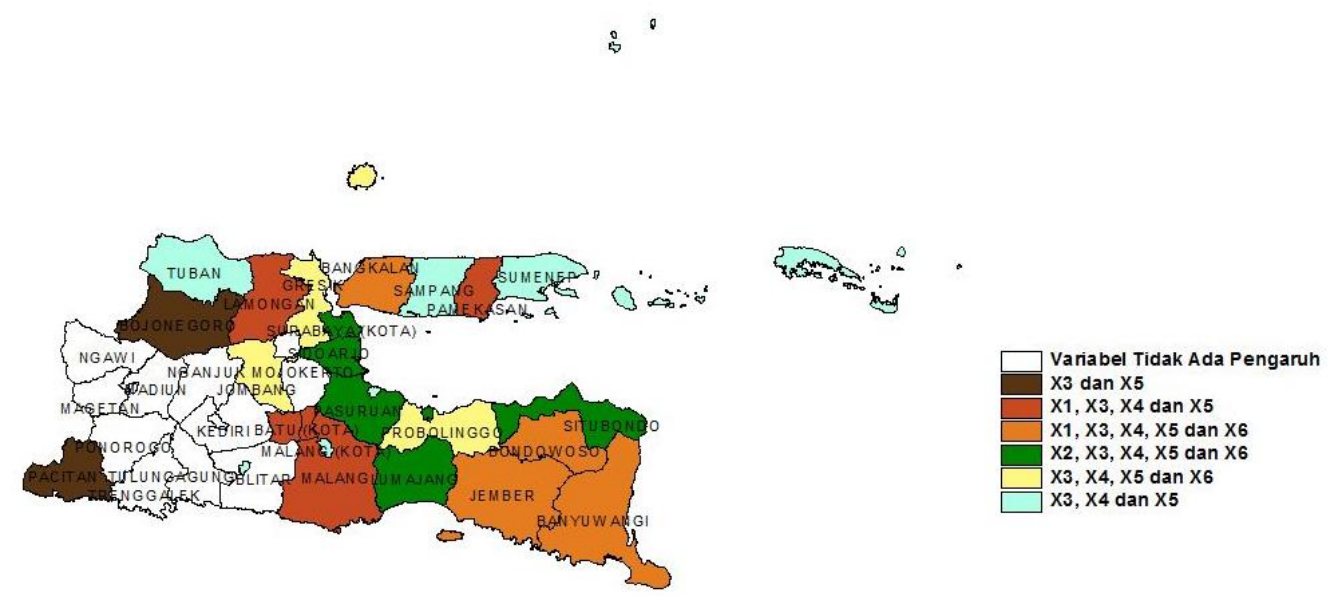

Gambar 2: Peta Persebaran Variabel Prediktor di Kabupaten/Kota Provinsi Jawa Timur.

Berdasarkan pengujian parameter secara parsial diketahui yang berpengaruh di masing-masing Kabupaten/Kota akan berbeda. Salah satu model GWR untuk Kota Surabaya (kode:37) adalah sebagai berikut:

$$
\hat{Y}_{37}=-41.49+0.08 X_{37,1}+1.59 X_{37,2}+0.06 X_{37,3}-0.85 X_{37,4}+1.19 X_{37,5}-5.05 X_{37,6}
$$

Jika variabel Kepadatan Penduduk $\left(X_{1}\right)$ naik sebesar satu persen maka persentase kriminalitas di Kota Surabaya akan meningkat sebesar $0.08 \%$ dengan ketentuan variabel lain tetap. Jika variabel Penduduk Miskin $\left(X_{3}\right)$ naik sebesar satu persen maka persentase kriminalitas di Kota Surabaya akan meningkat sebesar $0.06 \%$ dengan ketentuan variabel tetap.

\subsection{Pemilihan Model Terbaik}

Pemilihan model terbaik merupakan proses evaluasi dari model untuk mengetahui seberapa besar peluang masing-masing model terbentuk sesuai dengan data. Pada penelitian ini dibandingkan model OLS dan GWR berdasarkan kriteria $\mathrm{R}^{2}$ dan nilai AIC. 
Berdasarkan Tabel 6 diperoleh nilai $\mathrm{R}^{2}$ dan AIC yang optimum secara berturut-turut sebesar 0.91 dan 129.29 sehingga dinyatakan model GWR lebih baik dalam menganalisis faktor-faktor yang mempengaruhi persentase kriminalitas di Provinsi Jawa Timur dibandingkan dengan regresi linier berganda.

Tabel 6: Pemilihan model terbaik.

\begin{tabular}{ccc}
\hline Model & AIC & $\begin{array}{c}\text { Pseudo } \\
\mathbf{R}^{2}\end{array}$ \\
\hline OLS & 186.23 & 0.58 \\
GWR & 129.29 & 0.91 \\
\hline
\end{tabular}

\section{Simpulan}

Berdasarkan hasil analisis dengan metode GWR diketahui bahwa variabel $X_{1}, X_{2}, X_{3}, X_{4}, X_{5}$ dan $X_{6}$ berpengaruh secara signifikan terhadap persentase kriminalitas di Kabupaten/Kota Provinsi Jawa Timur. Model terbaik untuk persentase kriminalitas ditunjukkan dengan nilai $\mathrm{R}^{2}$ dan AIC pada GWR yang lebih optimum dibandingkan dengan metode OLS.

Adapun saran yang diberikan penulis yaitu agar pada penelitian selanjutnya dalam pemilihan variabel independen yang digunakan sebaiknya dikaji kembali sesuai dengan keilmuan kriminalitas sehingga akan diperoleh hasil yang lebih baik. Selain itu, pembobot yang digunakan dalam penelitian ini adalah kernel gaussian. Pada penelitian selanjutnya dapat menggunakan fungsi kernel yang lain sebagai pembobot dalam pengujian Geographically Weighted Regression (GWR).

\section{Daftar Pustaka}

Anselin, L. (2013). Spatial econometrics: methods and models. Springer Science \& Business Media.

Anselin, L., \& Bera, A. K. (1998). Spatial Dependence in Linier Regression Models With an Introduction to Spatial Econometrics. In Handbook of applied economic statistics. New York (US): Marcel Dekker.

[BPS] Badan Pusat Statistik. (2018a). Provinsi Jawa Timur dalam Angka tahun 2018. Surabaya (ID): Badan Pusat Statistik Jawa Timur.

[BPS] Badan Pusat Statistik. (2018b). Statistika kriminal 2018. Jakarta (ID): Badan Pusat Statistik.

Fotheringham, A. S., Brunsdon, C., \& Charlton, M. (2003). Geographically weighted regression: the analysis of spatially varying relationships. John Wiley \& Sons.

Gujarati, D. N., \& Porter, D. C. (2012). Dasar-dasar ekonometrika Edisi 5 buku 1 \& 2. Jakarta (ID): Salemba Empat.

LeSage, J. P. (2008). An introduction to spatial econometrics. Revue d'économie Industrielle, (123): 19-44.

Leung, Y., Mei, C.-L., \& Zhang, W.-X. (2000). Statistical tests for spatial nonstationarity based on the geographically weighted regression model. Environment and Planning A, 32(1): 9-32. 